\title{
Virtual reality as a main basis for forming modern educational technologies
}

\author{
Andrei Timokhin*, and Lubov Khoronko \\ Don State Technical University, 344002, Rostov-on-Don, Russia
}

\begin{abstract}
In the work from the position of modern pedagogical science, a number of difficulties (risks) associated with the use of virtual reality for educational purposes are considered. The practical significance of the results lies in solving the problem under study, which formulates general provisions on the specifics of VR as a method and means of education, notes the growth of digital educational technologies and the wide potential for their application in the future. Virtual reality in education is used as the information space, in which the student can not only obtain the necessary information, but also enter into the contact with the fictitious objects. Sinking (immersion) into the educational medium helps students to acquire the habits of interaction with the virtual objects, to develop methods of collective collaboration and to find confidence in the course presentation of its own projects. The process of creating the resources with the elements of interactivity, and also the selection of the necessary instrument means is a technological and a systematic problem for the teachers, who are mastering new information technologies. The purpose of the article is construction and substantiation of the effectiveness of the model of the use of technologies of virtual reality in the course of the instruction of schoolchildren in the system of additional formation.
\end{abstract}

\section{Introduction}

In modern pedagogy and psychology, real research in the field of virtual reality is extremely insufficient, in particular, such a problem is observed in relation to the educational effects of didactics and practice. However, the high material cost and complexity of the research itself plays not the last role in our country and abroad.

The problem of this study is that, in the classical sense, teaching means are the didactic tools of the teacher's and student's activities, educational equipment, and visual aids. VR is seen as a tool, but so far there are few training programs in a real virtual environment. For this reason, formally, virtual reality has not yet become a teaching tool in a broad sense.

The purpose of the research is to study virtual reality and similar information resources with elements of interactivity, which will act as the basic basis of modern educational technologies and will allow students to master the modeling of a picture of the world in the context of scientific knowledge.

\footnotetext{
* Corresponding author: andr-timohin2010@yandex.ru
} 
Virtual reality in pedagogy is most often used as a special information space where a student can receive certain information, establish contacts, and engage in educational and project activities. An example is the creation of a museum-library in a virtual space, which presents both scientific works and articles, as well as various kinds of creative photos and videos, memoirs of scientists from different historical periods, modern interactive information resources, such as video conferences, forums and models that are interactive in nature, as well as all kinds of courses and trainings. The creation of such information resources (similar to the "database") with interactivity elements is an important area of modern learning, allowing students to master the modeling of scientific ideas and directions.

Today, there is already a certain number of courses and lessons created using such technology as virtual reality. But all of them are still little accessible to the average user due to their high cost, but in a decade this technology will become available to everyone.

The essence of virtual reality in this study is more understood in the traditional cybernetic (software) sense and to coincide with the opinion of Russian scientists. It can be described by the following characteristics:

1) Modeling through 3D-images of objects that would be as close as possible to those in the real world. In this case, an analogy can be drawn with holographic images.

2) The ability to move or animation these objects. For example, a subject in our virtual space must be flexible to move it, there must be an opportunity to examine it from all sides, as well as some game mechanics, for example, space travel, or similar in biological cells, etc.).

3) All data processing should be carried out via the Internet in real time. These include the actions of our subject, for example, his movement, changing the tilt of the head, changing the image of the object, etc.

4) Creation through programming of the presence effect (a sense of the illusion of human interaction with objects or subjects in artificially created informational reality).

In general, virtual reality can be described as a technology of human interaction with a machine, which the most complete immersion of a user in an informational and interactive $3 \mathrm{D}$ environment. VR is a kind of special, separate, informational reality, which is designed to simulate ordinary reality. Depending on the goals of the researcher, the corresponding properties are introduced into the virtual environment, but, of course, this will in no way give a complete picture of the reproduction of real-world parameters.

\section{Methodology and Methods}

Today authors support the fact that VR technologies are means and methods of studying and forming the mental. When answering the question: "Is it possible to use VR in pedagogy, namely, in didactics?" I want to say that today we are not aware of any systematic developments in this area. Existing publications are often, if not theoretical, then theoretical in nature, but it's consider it appropriate to use VR technologies in education. The development of the model of the use of technologies of virtual reality in the instruction of students in the extra-curriculum activity was accomplished on the basis of the complex data analysis, obtained in the course of conducting the approval developed educational methods materials in the system of additional formation, structuring of information, generalization of the results of a study. 


\section{Results and Discussion}

A huge number of new educational opportunities can open up the use of virtual reality, as with traditional approaches, they are complex and expensive, and also require a considerable amount of time, which is not possible in the realities of modern education [1]. Among the positive qualities of using VR technologies in education, several points should be canceled:

1) Visibility. Modern 3D-graphics are able to show the smallest details of various kinds of processes, whether chemical experiments at the atomic level. But also nothing prevents to show the process itself much deeper, namely, what happens inside the atom [2]. Thus, this will provide an opportunity not only to obtain information about this phenomenon, but also to show in detail everything that happens to the student [3].

2) Security. In order to show how dangerous these or other situations are, we cannot subject students to certain tests, such as a fire or various kinds of natural disasters, and how to deal with them [4]. But with the use of virtual reality, it is possible for students to perform heart surgery, to control various techniques, for example, by train, to go on a space journey and even enter the Earth's orbit [5]. You can immerse the student in all this without the slightest threat to his life [6].

3) Involvement. The possibilities of virtuality allow you to influence the course of history and change various scenarios, solve problems, doing so in a playful way that is understandable to a young person. During such a lesson, a student can have many playing instruments with which he can use the eyes of a historical character to look at the historical world of the past or choose the right course on a ship or even set off to explore the human body from the inside [7].

4) Focus. The world of virtual reality appears to students at 360 degrees, which gives him the opportunity to examine it from all sides and will allow him to fully and completely concentrate on the object of study, without being distracted by the outside world [8].

5) VR lessons. One of the main features and characteristics of virtual reality should be noted the feeling of full presence, which is achieved due to the view from the feather face [9]. This completely and completely makes it possible to conduct lessons in the painted world [10].

But despite all the advantages mentioned above, it is customary to treat VR with caution, since it is identified with a certain world that is able to "lead" the subject away from real reality, and thereby form a virtual dependence. In this regard, one cannot fail to note the outstanding comparative analysis that was carried out by Atamuratov R. with respect to the difference between altered states of consciousness and the state of presence [11]. Okhunov I. showed that being in VR, unlike hypnosis, chemicals, etc., does not cause inadequate thinking, does not affect the degree of reflection, and is not characterized in any way by a feeling of duality, "alienation of oneself", "exit from the body", does not lead to the loss of arbitrariness and determination of activity [12]. Both these and many other features of virtual reality sufficiently illustrate its advantages (compared with the traditional, printed representation of the essence of education) and its potential for use in education, starting with primary school students [13].

However, there are other problems of using virtual reality as an educational tool, among them the most important and significant are:

1) Volume. Content creation requires tremendous resources, effort and time for any discipline, because all of them are quite voluminous. This may require dozens or even hundreds of small applications and tutorials. Companies that are ready to engage in such development will have to spend a significant amount of man-hours, moreover, this work will be able to recoup itself only after the full course of all lessons has been released [13]. 
2) Cost. It seems quite possible to buy such equipment for an educational institution and equip it with several classes with investments and state support. But in the case of students who, due to certain circumstances, are forced to study remotely, the purchase of VR equipment falls on his shoulders. Fortunately, modern smartphones are capable of displaying an image in virtual reality format thereby dividing the screen into two parts and, if there are special glasses, inserting a smartphone into which the student will have the opportunity to plunge into the process [14].

3) Functionality. To interact with VR, as with any other technology, it is important to know your specific language. For this, it is important to have the necessary tools with which it will be possible to develop content that is engaging and visual. But unfortunately, not many companies that deal with this manage to use all the capabilities of virtual reality, which leads to their failure to fulfill their functions $[15,16]$.

The didactic possibilities of the technologies of virtual reality were identified in the course of the instruction of students in the system of Primary School. The theoretical substantiation is given the need of applying the virtual reality as a means of the development of creative thinking in students and an effective tool of the creation of the immersive training medium. On the basis of a study working program has been prepared, as well as teaching aid and systematic recommendations for the teachers, who use technologies of virtual reality for conducting the training exercises.

The example of the picture in virtual reality is shown in Figure 1.

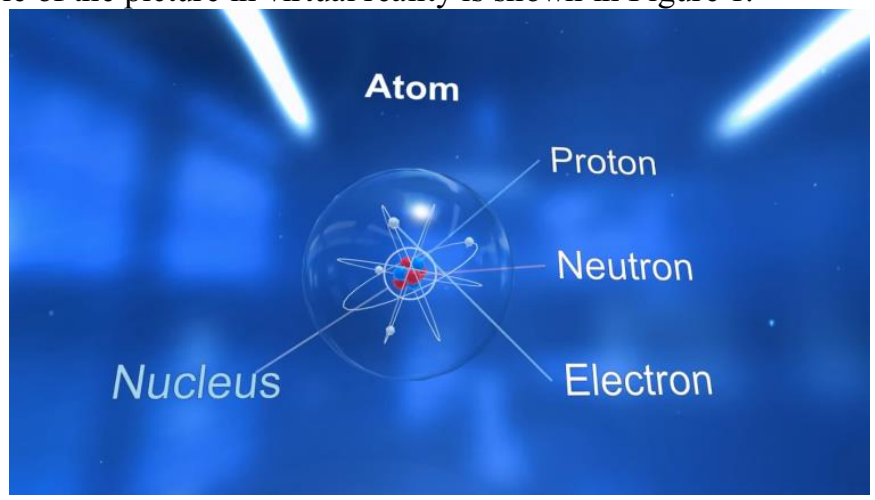

Fig. 1. Opportunities for studying physics in virtual reality. An example of the structure of the atom.

\section{Conclusion}

Thus, the following general provisions on the specifics of VR as a method and means of education can be formulated:

1) The training programs that were created in virtual reality showed a high potential for influence, which in turn was stimulated by the procedural and operational characteristics of the student's thinking, creativity, as well as its formation of a kind of cognitive trigger for further work and interest in getting an education, generating positive mental prostration.

2) The effect that didactic programs develop in virtual reality can be defined by a $3 D$ image of recognizable objects, a wide ability to perform actions with objects (animation), the presence effect, the interactivity of the situation, the implementation of visualization, abstract models, etc.

3) VR, which was used in education, appears as a method and means of both training and technology. This is due to the fact that VR training programs introduce significant specificity into the activities of a teacher and student, transforming the content of training, provide a new, informational method of presentation and understanding of the material, 
there is nothing more than high-tech didactic tools and act as a relatively rigid algorithm of actions, instructions, providing a guaranteed development effect.

4) The use of VR technologies in education, obviously has negative aspects. For example, a "super-shaped", visual representation of the content of education (with an incorrect design) can reduce the development of abstract concepts, symbolic thinking.

It should also be noted that digital technology is developing rapidly. Today, virtual reality is used to a greater extent in computer games, but there is no doubt that this technology will noticeably affect both our daily lives and the sphere of education in the coming decades. After all, good virtual classes related to visualizing the natural picture of the world, communicating in foreign languages and participating in various kinds of life situations will also be fascinating.

The success of virtual reality in the future is also discussed in publications on the digital economy, because this technology has great potential. But it is unlikely that it will be able to massively influence the practice of education in the near future, despite its huge potential. There is every reason to believe that this technology will become more widespread and popular when the cost of VR devices becomes less and they become more affordable.

\section{References}

1. H. Iriye, P.L. St. Jacques, Scientific Reports 11 (1), 4667 (2021).

2. G. Tao, B. Garrett, T. Taverner, E. Cordingley, C. Sun, Journal of NeuroEngineering and Rehabilitation 18 (1), 31 (2021).

3. A. Boschmann, D. Neuhaus, S. Vogt, M. Platzner, et al. Journal of NeuroEngineering and Rehabilitation 18 (1), 25 (2021).

4. H. Cai, T. Lin, L. Chen, et al., Trials 22 (1), 91 (2021).

5. C.N.W. Geraets, E.C.D. van der Stouwe, R. Pot-Kolder, W. Veling, Current Opinion in Psychology 41, 40-45 (2021).

6. P. Araiza-Alba, T. Keane, W.S. Chen, J. Kaufman, Computers and Education 164, 104121, (2021).

7. E. Gandolfi, K.W. Kosko, R.E. Ferdig, British Journal of Educational Technology 52 (2), 824-841 (2021).

8. O. Fedotova, E. Platonova, V. Latun, I. Filkevich, O. Igumnov, E3S Web of Conferences, ITSE-2020 210, (2020). DOI: 10.1051/e3sconf/202021022019.

9. O. Fedotova, V. Latun, E3S Web of Conferences, ITSE-2020 210, (2020). DOI: 10.1051/e3sconf/202021018047.

10. O. Fedotova, V. Latun, E3S Web of Conferences, ITSE-2020 210 (2020). DOI: $10.1051 / \mathrm{e} 3$ sconf $/ 202021018065$.

11. R. Atamuratov, International scientific review, LXVII (2019). URL: https:/cyberleninka.ru/article/n/the-educational-advantages-of-virtual-realitytechnologies.

12. I. Okhunov, Bulletin and education 21-1 (99), (2020). URL: https://cyberleninka.ru/article/n/sovershenstvovanie-pedagogicheskih-usloviyrazvitiya-otvetstvennogo-otnosheniya-k-virtualnoy-realnosti-u-buduschih-uchiteley.

13. E.T. Abdraimova, A.Zh. Shoibekova, K.B. Zhorabaev, Eurasian Union of Scientists 10-1 (79), (2020). URL: https://cyberleninka.ru/article/n/immersive-technologies-in-ahigher-school-in-the-modern-digital-reality. 
14. A.I. Azevich, RUDN Bulletin. Series: Informatization of education 4, (2019).https://cyberleninka.ru/article/n/virtual-reality-educational-and-methodologicalaspects.

15. A. Mokina, L. Khoronko, E3S Web of Conferences 175 (2020). https://www.e3sconferences.org/articles/e3sconf/pdf/2020/35/e3sconf_interagromash2020_15008.pdf DOI: $10.1051 / \mathrm{e} 3$ sconf $/ 202017515008$.

16. L. Khoronko, A. Mokina, E3S Web of Conferences 210, (2020). https://www.e3sconferences.org/articles/e3sconf/pdf/2020/70/e3sconf_itse2020_22021.pdf.

DOI: $10.1051 / \mathrm{e} 3$ sconf $/ 202021022021$. 